\title{
BREVE ANÁLISIS DE LA SENTENCIA DEL TRIBUNAL CONSTITUCIONAL ALEMÁN DE 21 DE JULIO DE 2010 EN RELACIÓN CON LA DESIGUALDAD ENTRE MATRIMONIO Y PAREJAS INSCRITAS EN MATERIA DE LA LEY DE IMPUESTOS A LA HERENCIA Y A LAS DONACIONES
}

Brief analysis of German Constitutional Court Judgement of 21 July 2010 in connection with the inequality between marriage and couples registered in the tax law of inheritance taxes and donations

\author{
CAROLINA RIVEROS FERRADA \\ Universidad de Talca \\ criveros@utalca.cl
}

Cómo citar/Citation

Riveros Ferrada, C. (2017)

Breve análisis de la Sentencia del Tribunal Constitucional alemán de 21 de julio de 2010 en relación con la desigualdad entre matrimonio y parejas inscritas en materia de la ley de impuestos a la herencia y a las donaciones. Revista Española de Derecho Constitucional, 110, 283-304. doi: https://doi.org/10.18042/cepc/redc.110.10

\section{Resumen}

En el presente comentario, se analiza una reciente sentencia del Tribunal Constitucional (TC) alemán referida a la desigualdad en el trato tributario respecto a los impuestos hereditarios entre matrimonios y las parejas inscritas. El TC alemán realiza un riguroso análisis del principio de igualdad (art. 3 de la Ley Fundamental alemana $[\mathrm{LF}])$ y la posible desigualdad de trato tributario fundada en la protección a la familia y esencialmente al matrimonio (art. $6 \mathrm{LF).}$

\section{Palabras clave}

Principio de igualdad; trato tributario; matrimonio; parejas inscritas. 


\section{Abstract}

This commentary discusses a recent ruling by the German Constitutional Court referred to the unequal tax treatment in respect of hereditary taxes between marriage and couples registered. The Court conducted a rigorous analysis of the principle of equality (art. 3 German Constitution) and the possible inequality of tax treatment on grounds of protection of the family and essentially the marriage (art. 6 German Constitution).

\section{Keywords}

Principle of equality; tax treatment; marriage; couples registered. 


\section{SUMARIO}

I. INTRODUCCIÓN. II. PRESUPUESTOS LEGALES Y CONSTITUCIONALES: 1. Matrimonio y parejas inscritas: 1.1. Constitución del vínculo de matrimonio y de parejas inscritas. 1.2. De los efectos del matrimonio y de las parejas inscritas. 1.3. De los regímenes patrimoniales. 1.4. Del derecho sucesorio. 1.5. De la separación y de las formas de terminación. 2. El art. 6, inc. 1, de la Ley Fundamental: 2.1. Garantía de instituto. 2.2. Norma que establece un principio axiológico fundamental. 2.3. Derecho. III. DOCTRINA DEL TRIBUNAL CONSTITU CIONAL RELATIVA A LA INSTITUCIÓN DE LAS PAREJAS INSCRITAS: 1. La sentencia del Tribunal Constitucional alemán. 2. La sentencia del Tribunal Constitucional de 17 de julio de 2002. 3. La sentencia del Tribunal Constitucional de 7 de julio de 2009. 4. La sentencia del Tribunal Constitucional de 18 de julio de 2012. 5. La sentencia del Tribunal Constitucional de 7 de mayo de 2013. IV. CONCLUSIONES. Bibliografía.

\section{INTRODUCCIÓN}

El 1 de agosto de 2001 se incorporó al ordenamiento jurídico alemán la Gesetz über die eingetragene Lebenspartnerschaft (Lebenspartnerschaftsgesetz-LPartG) ${ }^{1}$, es decir, la ley sobre parejas inscritas (LPI ${ }^{2}$. Esta ley regula sistemáticamente las relaciones jurídicas tanto personales como patrimoniales de las mencionadas parejas. Muscheler establece dos modelos, en uno de ellos se regula la completa igualación entre matrimonios y parejas inscritas y, en el otro, no se acepta dicha igualación (Muscheler, 2010: 227-236). Esta ley surgió por el vacío legal existente para parejas de

16. Februar 2001 (BGBI I S. 266). BVerfGE 105, 313-365.

2 Esta traducción, como las que siguen en el texto, son de mí autoría. En ellas se compatibiliza el tenor literal de las palabras con su uso jurídico de acuerdo al derecho alemán (Grziwotz, 2010: 1533). Este autor indica que no solo las parejas homosexuales, sino también las heterosexuales pueden inscribirse en el Registro Civil. Sin embargo, la gran mayoría de la doctrina estima que solo es aplicable a las parejas de la misma orientación sexual. Véase, a modo ejemplar, KG Berlin 1 Zivilsenat; en esta Sentencia de 3 de marzo de 2011 se resolvió, incluso, que un matrimonio homosexual celebrado de acuerdo a las normas holandesas correspondía por analogía a la eingetragene Lebenspartnerschaft. Disponible en: http://www. juris.de. 
la misma orientación sexual, que no tenían un instituto jurídico que las resguardase.

En el presente comentario se analiza una reciente sentencia del TC alemán referida a la desigualdad en el trato tributario respecto a los impuestos hereditarios entre matrimonios y las parejas inscritas. Este fallo responde la siguiente pregunta: ¿es posible fundar en el art. 6, inc. 1, LF una disposición referida a la protección constitucional de la familia y del matrimonio, un trato desigual con respecto a las parejas inscritas sin que afecte la garantía constitucional de la igualdad prevista en el art. 3, inc. 1, LF?; y, además, en este contexto, se plantea una segunda pregunta: ¡es constitucionalmente correcto considerar a las parejas inscritas simplemente como parientes lejanos o terceros para efectos tributarios? (Romswinkel, 2011: 277-279).

Para comprender la cercanía del matrimonio y las parejas inscritas en el derecho alemán, es menester examinar los aspectos básicos de la LPI, por ello, en la primera parte de este comentario se realizará un somero análisis comparativo de ambos institutos y se efectuará, además, un estudio de los presupuestos y los elementos básicos del art. 6, inc. 1, LF para comprender como el TC alemán ha ido desarrollado la discusión en relación con si es posible discriminar a las parejas inscritas con base en el matrimonio. Se advierte al lector que en el derecho alemán no se discute la eventual posibilidad de la aplicación de la normativa del matrimonio a las parejas inscritas, ello no es posible. En la segunda parte, se presentará la sentencia objeto de estudio y para entregar al lector una visión global en cuanto a la jurisprudencia del TC relativa a las parejas inscritas, se hará una remisión a importantes sentencias del TC que anteceden históricamente a la sentencia que se comenta, cuya importancia es vital y determina la línea jurisprudencial que se ha venido desarrollando desde la incorporación al ordenamiento jurídico alemán del instituto de las parejas inscritas.

\section{PRESUPUESTOS LEGALES Y CONSTITUCIONALES}

\section{MATRIMONIO Y PAREJAS INSCRITAS}

\subsection{Constitución del vínculo de matrimonio y de parejas inscritas}

El matrimonio en Alemania lo celebran un hombre y una mujer que declaran ante el oficial del Registro Civil que quieren unirse en vínculo matrimonial (Schwab, 2009: 29). Las parejas inscritas se constituyen por dos personas de igual sexo que, al igual que en el matrimonio, declaran que 
desean unirse en un vínculo para toda la vida (Wellenhofer-Klein, 2003: 15). En el año 2010, en Alemania se registraron 23000 parejas inscritas en comparación con el 2006-, lo que supone duplicar la cifra. Además, dicha cifra representa un $37 \%$ del total de las parejas homosexuales en dicho país ${ }^{3}$.

En cuanto a la constitución del vínculo, en el matrimonio la capacidad matrimonial requiere la mayoría de edad de ambos contrayentes, sin embargo, uno de ellos puede tener dieciséis años en el momento de contraer matrimonio siempre y cuando el Tribunal de Familia lo autorice y su representante legal no tenga razones fundadas para negarse al matrimonio ${ }^{4}$. De acuerdo al $\$ 1$ LPI, se exige la mayoría de edad de ambas personas; no existe la posibilidad de una autorización judicial. Además, una de las personas no puede estar actualmente casada o mantener una inscripción de pareja. Tampoco se puede ser pariente en línea directa, o ser hermanos, de cualquier clase.

\subsection{De los efectos del matrimonio y de las parejas inscritas}

En términos generales, los efectos del matrimonio y de las parejas inscritas son similares. Es decir, el $\$ 1353$ BGB establece la denominada comunidad conyugal, de la misma manera los $\$ \$ 2,4$ LPI exigen a los integrantes de la pareja a cuidarse, apoyarse y hacerse responsables recíprocamente.

3 Zahl der Woche Nr. 025 vom 21.06.2011. Deutschlandweit rund 23000 eingetragene Lebenspartnerschaften. WIESBADEN - „Im Jahr 2010 lebten in Deutschland rund 23000 gleichgeschlechtliche Paare als eingetragene Lebenspartnerschaft in einem Haushalt zusammen. Dies teilt das Statistische Bundesamt (Destatis) auf der Basis von Ergebnissen des Mikrozensus 2010, der größten jährlichen Haushaltsbefragung in Deutschland und Europa, mit. Das seit 2001 bestehende Lebenspartnerschaftsgesetz ermöglicht zwei Menschen gleichen Geschlechts ihrer Beziehung einen rechtlichen Rahmen zu geben. Im Mikrozensus wird dieser Familienstand seit 2006 abgefragt. Die Zahl der eingetragenen Lebenspartnerschaften hat sich seitdem nahezu verdoppelt. 2006 lebten knapp 12000 eingetragene Lebenspartnerschaften in Deutschland. Im Jahr 2010 gaben insgesamt 63000 Paare an, als gleichgeschlechtliche Lebensgemeinschaften zusammenzuleben. 37 \% der Paare gleichen Geschlechts waren somit nach dem Lebenspartnerschaftsgesetz registriert. Im Jahr 2006 traf das nur auf 19\% der rund 62000 gleichgeschlechtlichen Paare zu...» Disponible en: http://www.destatis.de/jetspeed/portal/cms/Sites/destatis/Internet/DE/Presse/ pm/zdw/2011/PD11__025__p002.psml.

4 \$\$ 1303 y ss. BGB. 
Respecto al nombre familiar, los cónyuges pueden utilizar un nombre común, que puede ser el nombre del marido o de la mujer y, además, les está permitido anteponer su propio nombre al nombre común ${ }^{5}$. Para las parejas inscritas existen las mismas posibilidades legales que para los cónyuges. En lo relativo al derecho de alimentos, las normas legales son muy similares, incluso el $\$ 5$ LPI se remite a las disposiciones del matrimonio ${ }^{6}$.

\subsection{De los regímenes patrimoniales}

El régimen de participación en los gananciales (Zugewinngemeinschaft ${ }^{7}$ ) fue incorporado como régimen legal matrimonial al derecho alemán por medio de la Ley de Igualdad de Derechos entre Hombres y Mujeres, de 18 de junio de 1957. El fundamento de este régimen es la igualdad hombres y mujeres, específicamente la protección del cónyuge que realiza las labores domésticas o de cuidado de los hijos. El antiguo sistema era inconstitucional, pues vulneraba el principio de igualdad entre hombres y mujeres. En el derecho de familia alemán, desde el 1 de julio de 1958, existe el régimen de la participación en los gananciales como régimen legal matrimonial. No obstante ello, la legislación prevé dos regímenes alternativos: el régimen de separación de bienes ${ }^{8}$ y el régimen de sociedad conyugal ${ }^{9}$. Por el contrario, no existe un régimen legal matrimonial para las parejas inscritas, aunque las parejas pueden elegir el denominado régimen de compensación de comunidad (Ausgleichsgemeinschaft), que se asemeja muchísimo al régimen de participación en los gananciales. Con todo, no existe la posibilidad de regímenes alternativos como en el matrimonio.

\subsection{Del derecho sucesorio}

El cónyuge sobreviviente hereda junto con los descendientes una cuarta parte de la herencia ${ }^{10} \mathrm{y}$, en el caso de que los cónyuges hayan vivido bajo el

$\$ 1355$ BGB.

6 Compárese $\$ \$ 1360$ y ss con $\$ 5$ LPI. Así lo establece también Schwab, quien indica que el derecho de alimentos conyugales es el modelo de los alimentos de las parejas inscritas (Schwab, 2009: 461).

$7 \$ \$ 1363$ y ss. BGB.

$8 \$ 1414$ BGB.

9 \$S 1415 ss. BGB.

$10 \$ 1931$ BGB. 
régimen de participación en los gananciales durante la vigencia del matrimonio, se deberá incrementar la cuota legal en un cuarto ${ }^{11}$. Las parejas inscritas poseen similares derechos que los cónyuges sobrevinientes; existe, incluso, la posibilidad de incrementar la cuota legal hereditaria, una cuestión que ha sido arduamente discutida por la doctrina ${ }^{12}$. Coincide la normativa legal en cuanto brindarles tanto a los cónyuges como a la pareja la posibilidad de redactar un testamento mancomunado.

\subsection{De la separación y de las formas de terminación}

En lo relativo a la separación del matrimonio, se requiere la inexistencia de una comunidad de hogar y de la negativa por parte de uno de los cónyuges de restablecer dicha comunidad. En este caso, se pueden reclamar alimentos, según las condiciones de vida y la situación patrimonial y de ingresos de los cónyuges. Ahora bien, en relación con las parejas inscritas, el $\$ 12$ LPI es en su primera parte idéntica al $₫ 1361 \mathrm{BGB}^{13}$, aún más, existe una remisión a las disposiciones legales del matrimonio ${ }^{14}$.

$11 \$ 1371$ BGB. Esta repartición de los bienes del causante se denomina en la doctrina alemana pauschaler familienrechtlicher Zugewinnausgleich.Véase, al respecto, Frank (2003: 30), Schwab y Koch $(2000: \$ 1371,12)$ y (Kessal-Wulf (1999: \$1931, 24).

12 Se indica que el $\$ 1371$ BGB ya es criticado, debido a su bajo contenido de justicia en relación con los hijos y también que fue formulado en atención al matrimonio tradicional para proteger a las esposas dueñas de casa. Con lo cual es muy dificil justificar su aplicación para el caso de las parejas homosexuales que, por lo general, no desarrollan su vida en común con lo que por analogía sería un modelo tradicional de matrimonio (Wellenhofer-Klein, 2003: 123).

13 El $\$ 12$ LPI dispone: «Unterhalt bei Getrenntleben. Leben die Lebenspartner getrennt, so kann ein Lebenspartner von dem anderen den nach den Lebensverhältnissen und den Erwerbs-und Vermögensverhältnissen der Lebenspartner angemessenen Unterhalt verlangen». Ahora bien, respetándose la diferenciación de la terminología el \$1361 BGB prevé: «Unterhalt bei Getrenntleben. Leben die Ehegatten getrennt, so kann ein Ehegatten von dem anderen den nach den Lebensverhältnissen und den Erwerbs-und Vermögensverhältnissen der Ehegatten angemessenen Unterhalt verlangen».

14 Así lo establece la frase final del $\$ 12$ LPI, puesto que indica: «Die $\$ \$ 1361$ und 1609 des Bürgerlichen Gesetzbuchs gelten entsprechend». 
Respecto al divorcio ${ }^{15}$, se requiere la ruptura de la convivencia entre los cónyuges $^{16}$. El concepto de fracaso matrimonial (Scheitern der Ehe) no fue utilizado en la terminología de las parejas inscritas, es decir, no existe como una causa general. En el $₫ 15$ LPI se establecen como causas de terminación de las parejas: la disolución de común acuerdo; la disolución debido a la separación sin posibilidades de reconciliación de un año. Para Schwab (2009: 469), en este caso, habría una semejanza con la causal genérica del $\$ 1565$ BGB. Asimismo, las parejas inscritas también pueden disolverse en razón de tres años de separación. Esta última causal también puede asimilarse a la presunción de derecho del $\$ 1566$, inc. 2 , BGB, la cual considera al matrimonio arruinado si los cónyuges han estado separados tres años. Finalmente, existe como causa de disolución de las parejas inscritas la terminación en razón de situaciones intolerables; en este caso, no se requiere de la separación, lo que permite pensar que se agregan a esta causa elementos de tipo subjetivos, que recuerdan al derogado divorcio culpable. Al igual que para el divorcio, se establece una cláusula de dureza, por ello, a pesar de cumplirse con los requisitos para la terminación de la pareja inscrita, ella no se permite.

En síntesis, se puede indicar que claramente el matrimonio fue el modelo para concebir la institución de las parejas inscritas en el ordenamiento jurídico alemán.

\section{EL ART. 6, INC. 1, DE LA LEY FUNDAMENTAL}

Ahora bien, me referiré someramente al art. 6, inc. 1, LF debido a que esta norma constituye la base fundamental del posible trato desigual entre los cónyuges y las parejas inscritas.

15 «El divorcio alemán está regido desde el año 1976 por la idea del divorcio-remedio a diferencia del denominado divorcio-sanción, puesto que en el derecho alemán solo se constata la ruptura irremediable de la convivencia matrimonial. Por ello es irrelevante cuál de ambos cónyuges es responsable por aquel quiebre en la comunidad matrimonial, más aún si se considera que ni los cónyuges ni el juez — muchas vecesestán en la situación de determinar cuáles fueron las causas de la ruptura matrimonial y con qué intensidad afectaron a la relación matrimonial» (Riveros y López, 2008: 99).

16 «[...] el matrimonio está arruinado, cuando no existe una comunidad de vida entre los cónyuges y no es de esperar que los cónyuges restituyan dicha comunidad» (Riveros y López, 2008: 99). 
De acuerdo al art. 6, inc. 1, LF, el matrimonio y la familia están amparados en una protección estatal especial ${ }^{17}$. La norma incluye tres significados: en primer lugar, lo que la doctrina ha denominado la "garantía de instituto» (Institutsgarantie) (Di Fabio, 2003, 994); en segundo lugar, la norma que establece un principio axiológico fundamental (wertentscheidende Grundsatznorm ${ }^{18}$ ); y, en tercer lugar, el derecho (Abwehrrecht) (Kingreen, 1997: 402).

\subsection{Garantía de instituto}

La LF protege el matrimonio ${ }^{19}$ y la familia ${ }^{20}$. Aunque ambas instituciones, sin embargo, no están definidas (Ott, 1998: 117). Steiner define el matrimonio como «una pareja con igualdad de derechos, en que un hombre y una mujer, sobre la base de una promesa jurídicamente vinculante, asumen en una comunidad para toda la vida una responsabilidad parental común $»^{21}$. La institución del matrimonio se garantiza por la observancia de determinados principios estructurales ${ }^{22}$, entre otros principios, pertenecen a esta categoría la libertad para contraer matrimonio (Eheschließungsfreiheit), el matrimonio civil con formalidades (eine formalisierte Zivilehe ${ }^{23}$ ), la diferencia de sexo (die Verschiedengeschlechtlichkeit ${ }^{24}$ ), la monogamia (die Monogamie $^{25}$ ) y la indisolubilidad (eine Lebenslänglichkeit der Ehe ${ }^{26}$ ). La protección especial del matrimonio no quiere decir que otras comunidades de vida no puedan ser aceptadas ni respetadas por el ordenamiento jurídico. Así, por

17 Véanse también los arts. 8, 12 EMRK; para una apreciación histórica de la norma constitucional, véase también Schwab (1976: 893 y ss.)

18 BVerfG FamRZ 1957, 82, 83 (Badura, 2001: 88; Rauscher, 2001: 34;b y Steiner, 2005: 433 y ss.).

19 BVerfG NJW 1993, 3316, 3317 (Von Münch et al., 2000: arts. 6, 4)

20 BVerfGE 10, 59, 66.

21 Barcia y Riveros (2011: 261); «[...] eine gleichberechtigte Partnerschaft, in der Mann und Frau auf der Grundlage eines rechtsverbindlichen Versprechens zur „Gemeinschaft des ganzes Lebens" umfassend zueinander stehen und gemeinsame Elternverantwortung wahrnehmen«(Steiner, 2005: 442); BVerfG FamRZ 1980, 319, 323..

22 BVerfGE 53, 224 , 245; BVerfGE 62, 322, 330; Gernhuber (1981: 722) .

23 BVerfGE 62, 323, 330; Gernhuber y Waltjen-Coester (2006: $\$ 5$ I, 3 y ss.).

$24 \quad$ BVerfG NJW 1993, 3316, 3317.

25 BVerfGE 48, 327, 339; Von Münch et al. (2000: arts. 6, 8).

26 Von Münch et al. (2000: arts. 6, 10). 
ejemplo, las uniones de hecho gozan de la protección del art. 2, inc. 1, de la $\mathrm{LF}^{27}$.

En relación con la familia, se protege constitucionalmente ${ }^{28}$, la comunidad existente entre padre e hijos, la denominada familia pequeña o nuclear (Kleinfamilie $\left.{ }^{29}\right)$. La protección se extiende tanto a las familias que se fundan en el matrimonio como a aquellas que se basan en uno o ambos padres con sus hijos no matrimoniales ${ }^{30}$.

\subsection{Norma que establece un principio axiológico fundamental}

La norma constitucional comprende una prohibición de dañar (ein Schädigungsverbot), una prohibición de diferenciar (ein Differenzierungsverbot) y un mandato de fomentar (ein Förderungsgebot). El Estado está obligado, por una parte, a dejar de hacer todo aquello que pueda dañar al matrimonio y a la familia y, por otro lado, a fomentar ambas instituciones ${ }^{31}$. Ambas prohibiciones significan para los ámbitos del derecho social ${ }^{32} \mathrm{y}$ tribu$\operatorname{tario}^{33}$ que el legislador no puede crear ni tampoco tolerar ningún detrimento del matrimonio o de la familia en comparación con personas solteras ${ }^{34}$. En cuanto al mandato de fomento, este implica, generalmente, una descarga o exoneración económica para la familia. Esta caracterización de la norma que establece un principio axiológico fundamental (wertentscheidende Grundsatznorm) vale tanto para todo el derecho público como para el derecho privado ${ }^{35}$.

27 Badura (2001: 90) y Ott (1998: 117 y ss.).

28 BVerfGE 10, 59, 66; BVerfGE 48, 327, 339; BVerfGE 80, 81, 90 (Lecheler, 1979: 2 y ss.).

29 Pertenece a este grupo los hijos adoptivos, los hijos de la pareja y los menores bajo custodia (Kingreen, 1997: 402).

30 La comunidad entre la madre y los hijos no matrimoniales como asimismo la comunidad entre el padre y los hijos no matrimoniales son reconocidos como familia. BVerfG FamRZ 2006, 385 (comentarios de Luthin, 2006: 386; Badura, 2001: 87; y Di Fabio, 2003: 994)

31 BVerfGE 61, 18, 25; BVerfGE 75, 382, 392 (Badura, 2001: 88).

32 BVerfGE 67, 186.

33 BVerfGE 13, 290, 296.

34 Gernhuber y Waltjen-Coester (2006: \$5 II 17).

35 BVerfGE 6, 55; BVerfGE 105, 313, 346; BVerfGE 107, 205, 212 (Steiner, 2005: 434). 


\subsection{Derecho}

Como derecho fundamental el art. 6, inc. 1, LF protege también los derechos de libertad del matrimonio y de la familia ${ }^{36}$. Cada individuo tiene la libertad de contraer matrimonio. En esta categoría se protege tanto la libertad

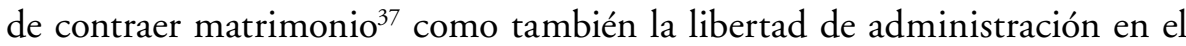
matrimonio. La libertad para liberarse de un matrimonio está comprendida y garantizada en la libertad de divorciarse ${ }^{38}$ y en la libertad para poder volverse $\operatorname{a~casar~}^{39}$.

\section{DOCTRINA DEL TRIBUNAL CONSTITUCIONAL RELATIVA A LA INSTITUCIÓN DE LAS PAREJAS INSCRITAS}

\section{LA SENTENCIA DEL TRIBUNAL CONSTITUCIONAL ALEMÁN ${ }^{40}$}

La sentencia estudió la desigualdad de trato de los matrimonios y las parejas inscritos en la Ley de Impuestos a la Herencia y las Donaciones (LIHD) (versión de 2008), basándose en que para los recurrentes algunas disposiciones de dicha ley eran contrarias al art. 3, inc. 1, LF.

El primer recurrente era el único heredero universal de su pareja fallecida el día 25 de agosto de 2001. Los impuestos que debía pagar, por un patrimonio imponible ascendiente a 279050 marcos alemanes (DM), eran de 61295 DM, ya que se incorporaba al recurrente en el grupo III de la escala tributaria $^{41}$, se reconocía una exención de $10000 \mathrm{DM}$ de acuerdo al $\$ 16$, inc. 1.5 LIHD y se aplicaba una tasa de impuesto de $23 \%$. Si a este supuesto se le hubiese aplicado las reglas que regulan al cónyuge sobreviviente, el heredero

36 Gernhuber y Waltjen-Coester (2006: $\$ 5$ III, 31) y Kingreen (1997: 401 y ss.).

37 BVerfGE 31, 58, 69 (Von Münch et al., 2000: arts. 6. 21 y ss.).

38 BVerfGE 31, 58 (Gernhuber/Waltjen-Coester $\$ 5$ II, 17; Larenz y Wolf, 2004: $\$ 2$, 75 ss.; y Rauscher, 2001: 36). Este principio se incorporó al derecho de familia alemán por medio de la Ley de Igualdad de Derechos entre Hombres y Mujeres, de 18 de junio de 1957. Véase Bosch (1954: 149 y ss.).

39 BVerfGE 31, 58, 82.

40 BVerfG, 1 BvR 611/07 vom 21-07-2010, Inc. 1-122. Disponible en: http://www. bverfg.de/entscheidungen/rs20100721_1bvr061107.html. Pressemitteilung 63/2010 vom 17- August-2010. Véase, entre otros, Strohal (2010: 481-483).

41 El grupo III pagaba entre un $17 \%$ y $50 \%$. 
hubiese quedado dentro del grupo I de la escala tributaria ${ }^{42}$, la exención hubiese sido de $600000 \mathrm{DM}(307000 €)$ y la exención de manutención hubiese sido de 500000 DM (256 $000 €)$. Por lo tanto, en comparación con el recurrente, un cónyuge sobreviviente hubiese quedado bastante más beneficiado.

La segunda recurrente era heredera de su pareja, quién falleció el día 28 de febrero de 2002. Los impuestos fueron establecidos en la suma de $12090 €$, de acuerdo a un patrimonio imponible de $58500 €$. Asimismo, esta contribuyente también fue incorporada en el grupo III y se le aplicó una exención de $5200 €$ e, igual que en el primer caso, una tasa de impuestos de $23 \%$.

En ambos casos, el Tribunal Superior Tributario rechazó los recursos interpuestos por las parejas sobrevivientes y, por este motivo, recurrieron al TC. Ellos ponderaban la normativa tributaria, esto es, los $\$ \$ 15$, inc.s 1.16, 1.17 y 1.19 LIHD, como atentatoria del art. 3, inc. 1, LF. Los recurrentes consideraron, por lo tanto, que se violaba el principio de igualdad ${ }^{43}$.

En primer lugar, el $₫ 15$, inc. $1, \mathrm{LIHD}^{44}$ se refería a los grupos tributarios. Como ya se ha mencionado, los cónyuges se incorporaban al grupo I y las parejas inscritas al grupo III, ya que, estas no tenían un trato tributario distinto al resto de los contribuyentes, se veían como simples terceros. Incluso se consideraban a los cónyuges divorciados en una mejor situación impositiva.

Segundo, el $\$ 16$, inc. $1, \mathrm{LIHD}^{45}$ establecía una diferencia sustancial en las exenciones tributarias al impuesto a las herencias y donaciones, puesto que

42 El grupo I pagaba entre un $7 \%$ y un $30 \%$.

43 Todas esta normas legales se consideraron insconstitucionales, ya que violaban el principio de igualdad establecido en el art. 3, inc. 1, de la Ley Fundamental. BVerfG, 1 BvR 611/07 vom 21-07-2010, inc. 1-122, Disponible en: http://www.bverfg.de/ entscheidungen/rs20100721_1bvr061107.html.

$44 \$ 15$ ErbStG. Steuerklassen (1) Nach dem persönlichen Verhältnis des Erwerbers zum Erblasser oder Schenker werden die folgenden drei Steuerklassen unterschieden: Steuerklasse I: 1. der Ehegatte, 2. die Kinder und die Stiefkinder, 3. die Abkömmlinge der in Nummer 2 genannten Kinder und Stiefkinder, 4. die Eltern und Voreltern bei Erwerben von Todes wegen. Steuerklasse II: 1. die Eltern und Voreltern, soweit sie nicht zur Steuerklasse I gehören, 2. die Geschwister, 3. die Abkömmlinge ersten Grades von Geschwistern, 4. die Stiefeltern, 5. die Schwiegerkinder, 6. die Schwiegereltern, 7. der geschiedene Ehegatte; Steuerklasse III: alle übrigen Erwerber und die Zweckzuwendungen.

$45 \$ 16$ ErbStG Freibeträge.(1) Steuerfrei bleibt in den Fällen des $₫ 2$ Abs. 1 Nr. 1 der Erwerb. 1. des Ehegatten in Höhe von 600.000 Deutsche Mark / 307000 Euro; 2. der Kinder im Sinne der Steuerklasse I Nr. 2 und der Kinder verstorbener Kinder im Sinne der Steuerklasse I Nr. 2 in Höhe von 400000 Deutsche Mark / 205000 Euro; 
el monto de las exenciones para los cónyuges sobrevivientes correspondía a $307000 €$ y para las parejas sobrevivientes $5200 €$.

En relación con el $\$ 17 \mathrm{LIHD}^{46}$, sobre la exención por manutención, es preciso señalar que el cónyuge sobreviviente se veía protegido con una exención de $256000 €$. Al examinar la situación de las parejas inscritas, ellas no se veían favorecidas por dicha exención, es decir, la exención por manutención no estaba contemplada en la ley para el caso de las parejas inscritas.

Finalmente, el $\$ 19$ LIHD establecía una tasa tributaria de acuerdo al grupo tributario al cual se incorporaba el contribuyente.

Ahora bien, el Tribunal Superior Tributario consideró que, si bien por medio de una interpretación analógica de las normas relativas a la LIHD —es decir, los $\$ \$ 15,16,17$ y 19 LIHD - podría igualarse el trato de los cónyuges con las parejas sobrevivientes, no necesariamente debía efectuarse. Además, estimó que el art. 14 , inc. $1, \mathrm{LF}^{47}$ — una norma relativa a la protección constitucional del derecho a suceder - debe ser comprendido y analizado en consideración al art. 6 inc. 1, LF ${ }^{48}$. En efecto, el principio de la familia en materia tributaria actúa como límite en las tasas impositivas.

En este contexto, fueron oídos diversos estamentos de influencia nacional, en primer lugar, la Cámara Nacional de los Contadores calificó de correcta la desigualdad de trato entre cónyuges y parejas inscritas, no así la igualdad de trato entre parejas inscritas y terceros, sosteniendo que los matrimonios y las parejas inscritas no son lo mismo porque la orientación sexual es diferente. Criticó fuertemente la igualdad de trato de las parejas y terceros, ya que consideró que la relación entre la pareja y el causante, tanto desde una

3. der übrigen Personen der Steuerklasse I in Höhe von 100000 Deutsche Mark / 51200 Euro; 4. der Personen der Steuerklasse II in Höhe von 20000 Deutsche Mark / 10300 Euro; 5. der Personen der Steuerklasse III in Höhe von 10.000 Deutsche Mark / 5200 Euro.

$46 \$ 17$ ErbStG. Besonderer Versorgungsfreibetrag. (1) Neben dem Freibetrag nach $\$ 16$ Abs. 1 Nr. 1 wird dem überlebenden Ehegatten ein besonderer Versorgungsfreibetrag von 500.000 Deutsche Mark / 256000 Euro gewährt. Der Freibetrag wird bei Ehegatten, denen aus Anlaß des Todes des Erblassers nicht der Erbschaftsteuer unterliegende Versorgungsbezüge zustehen, um den nach $\$ 14$ des Bewertungsgesetzes zu ermittelnden Kapitalwert dieser Versorgungsbezüge gekürzt.

$47 \mathrm{El}$ art. $14 \mathrm{LF}$ prevé «Das Eigentum und das Erbrecht werden gewährleistet. Inhalt und Schanken werden durch die Gesetze bestimmt»; esto es, la propiedad y el derecho a suceder están garantizados.

$48 \mathrm{El}$ art. $6 \mathrm{LF}$ dispone que "Ehe und Familie stehen unter dem besonderen Schutze der staatlichen Ordnung»; es decir, que el matrimonio y la familia están bajo la especial protección estatal. 
perspectiva jurídica como económica, no es comparable a la relación de un pariente lejano. Las parejas construyen una base económica para el desarrollo de la familia y es natural que el sobreviviente disfrute, después de la muerte de su pareja, dicho bienestar económico. La antedicha razón no es aplicable a un pariente lejano y, por ello, la situación de la pareja sobreviviente y el pariente lejano no es comparable.

En segundo lugar, la Cámara Nacional de Abogados sostuvo que el trato desigual entre cónyuges y parejas inscritas era justificado, mas consideró que la inclusión de las parejas inscritas en el grupo III y una bajísima exención eran inadecuadas, puesto que las parejas inscritas eran consideradas como parientes lejanos.

Finalmente, la Agrupación de Lesbianas y Homosexuales esgrimió la inconstitucionalidad de las normas de la LIHD, debido a que transgredían tanto el art. 3, inc. 1; como el art. 14, inc. 1, línea 1, LF. Se argumentó que la necesidad de crear un patrimonio y de mantener un nivel de vida, especialmente en la vejez, no difiere entre los cónyuges y las parejas inscritas, y se sostuvo, fundamentalmente, que, en realidad, la discriminación era en razón de la orientación sexual. Esta agrupación también aludía a que el trato igualitario de las parejas inscritas con parientes lejanos no tiene ninguna justificación.

El TC efectuó un concienzudo estudio de la constitucionalidad de las normas tributarias. A continuación, se revisan los principales aspectos del fallo.

El TC sostuvo que la igualdad exige que todas las personas sean tratadas por la ley de la misma manera, esto es, igual a los iguales, desigual a los desiguales. Por ello, está prohibido dar beneficios a un grupo de personas y negárselas a otras sin que existan razones fundadas para dicha diferenciación.

En el ámbito del derecho tributario, el marco legal es bastante amplio tanto en los objetos de los impuestos como en la determinación de las tasas de impuestos. Con todo, el legislador debe considerar dos principios limitadores lineamientos fundamentales: Gebot der Ausrichtung des Steuerlast am Prinzip der finanziellen Leistungsfähigkeit (mandato de orientación de la carga tributaria al principio de la capacidad financiera) y Gebot der Folgerichtigkeit (mandato de consecuencia).

La libertad del legislador es especialmente amplia cuando se trata de normar situaciones de vida distintas, en la cuales los aludidos, a través de sus propias conductas, pueden adaptarse a las diferentes reglas. Por el contrario, los límites del legislador son muchísimo más extensos si las desigualdades respecto de las libertades garantizadas constitucionalmente se manifiestan profunda y fuertemente, y el individuo tiene menos posibilidades por medio de su propia conducta de disminuir las desventajas que se generan. Se transgrede el art. 3, inc. 1, LF, cuando a un grupo de individuos en comparación con 
otro grupo, se le trata de forma distinta, a pesar de que entre ambos grupos no existe ninguna diferencia, la cual pueda justificar el tratamiento desigual.

El TC alemán argumenta que un análisis de igualdad debe ser muy riguroso, en los casos en que el legislador establezca una diferenciación respecto de personas de diversa orientación sexual. La decisión de matrimonio o de una inscripción de pareja está íntimamente ligada a la orientación sexual de una persona. En efecto, las normas que regulan los derechos y deberes de parejas inscritas, comprenden, por regla general, a personas homosexuales y, a su vez, disposiciones que establecen derechos y obligaciones de cónyuges, generalmente dirigidas a individuos heterosexuales.

Por ello, la diferencia que existe en el trato tributario entre cónyuges y parejas inscritas en materia de derecho sucesorio - la cual necesariamente va unido a consideraciones acerca de la orientación sexual de una personarequiere una concreta justificación que permita diferenciar entre ambas formas de vida.

El TC no advirtió una diferencia tan esencial que permita fundar el trato desigual en materia de impuestos hereditarios. Así, que el TC resolvió que el el art. 6, inc. 1, LF no permite justificar por si solo una desigualdad de trato. El hecho de que el matrimonio esté protegido constitucionalmente genera que, respecto de otras formas de vida, el matrimonio sea discriminado positivamente. Verbigracia, el financiamiento estatal de la inseminación artificial o las normas relativas al derecho de alimentos, protección social y derecho tributario, entre otras. Con todo, si el trato positivo significa una discriminación a otras formas de vida, no se puede, simplemente, efectuar una remisión general y abstracta al art. 6, inc. 1, LF, como justificación.

Por lo que respecta al art. 3, inc. 1, LF, el TC lo analiza de forma separada y determina si, y de qué manera, los terceros — en este caso concreto, las parejas inscritas - requieren un trato igualitario respecto a los cónyuges.

En la doctrina de derecho tributario se justifican las altas exenciones, tanto para los cónyuges como para los hijos, en razón de la comparación respecto de terceros por la bajísima capacidad o participación de esas personas en la sucesión del causante. Entre otras razones, se argumenta lo siguiente:

a) Los cónyuges y los hijos habrían participado durante la vida del causante de su patrimonio y de un nivel de vida que se pretende mantener. El patrimonio del causante no solo fue formado para él, sino que también para su familia; $y$, en ese sentido, los parientes más cercanos han participado muchas veces activamente en la formación de dicho patrimonio. Es preciso indicar, además, que la sucesión cumple una función de reemplazar los alimentos. 
b) La sucesión al reemplazar los alimentos justifica la exención. El principio de la familia que determina el derecho sucesorio no permite de ninguna manera justificar la desigualdad de trato existente entre cónyuges y parejas inscritas.

c) Además, las parejas inscritas viven como los cónyuges, es decir, en una comunidad de vida seria y participan durante la vida en común de un estándar económico similar al de su pareja, por lo que no existen diferencias entre ambas formas de convivencia. Las exenciones, por lo tanto, no tiene una justificación en la medida en que solo favorezcan a los cónyuges.

Lo cierto es que, en la tradición jurídica alemana, siempre se ha reconocido a la familia — esto es, a los cónyuges y parientes más próximos- una condición especial que justifica sus privilegios tributarios. Con todo, las parejas inscritas se estiman como una institución familiar para una pareja de igual orientación sexual que perdura en el tiempo ${ }^{49}$.

El fallo del TC resolvió que la sentencia del Tribunal Supremo Tributario violó el art. 3, inc. 1, LF, ya que, las normas de la LIHD transgredían el principio de igualdad sin una justificación que hiciese aceptable un trato desigual; y, en razón de ello, no fue necesario referirse a si era correcto o no que las parejas inscritas fuesen igualadas a parientes lejanos o terceros. La misma razón se argumentó para no efectuar un análisis de constitucionalidad del art. 14, inc. 1, LF.

En resumen, el TC resolvió que los $\$ \$ 16$, inc. 1.17 y 15 inc. 1 en relación con el $\$ 19$ LIHD eran inconstitucionales porque transgredían el principio de igualdad; y, por este motivo, se acogieron los recursos y fue devuelta la causa al Tribunal Superior Tributario.

Finalmente, se le exigió al legislador un cambio de la normativa tributaria que debía producirse antes del 31 de diciembre de 2010 (Messner, 2010: 1875 -1879).

\section{LA SENTENCIA DEL TRIBUNAL CONSTITUCIONAL DE 17 DE JULIO DE $2002^{50}$}

En términos generales, en este fallo se discutió ${ }^{51}$, en relación con el tema de este comentario, acerca de la compatibilidad de la LPI con el art. 6, inc. 1,

49 Véase BVerfGE 124, 199, 206.

50 BVerfG NJW 2002, 2543.

51 También se discutió respecto de un problema der constitucionalidad formal, es decir, si la separación de la LPI entre una parte libre de consentimiento y otra que requiere 
LF. El TC señaló que no se pudo establecer ninguna violación a dicha disposición constitucional, puesto que ella no transgredía ni la libertad para contraer matrimonio ni el matrimonio como instituto. Incluso en el caso de que existiese una pareja inscrita como tal, ni aun así se les impedían a los individuos contraer matrimonio.

El instituto del matrimonio no se veía perjudicado con la institución de las parejas inscritas. No existía ninguna modificación del matrimonio debido a la incorporación de la LPI al ordenamiento jurídico. Se reconoció que se reprodujo al matrimonio para el caso de la LPI, mas ello no afectó de ninguna manera a los cónyuges. Tampoco se establecían perjuicios en cuanto al mandato de fomento, ya que no es posible extraer de dicho mandato la posibilidad de perjudicar a otras comunidades de vida. Lo que realizó la LPI es, en definitiva, darle una especial protección jurídica a una determinada comunidad de vida como, asimismo, establecer sus derechos y sus obligaciones (Wellenhofer-Klein, 2003: 24).

\section{LA SENTENCIA DEL TRIBUNAL CONSTITUCIONAL DE 7 DE JULIO DE 200952}

En este caso se discutió acerca de la posible transgresión del art. 3, inc. 1, LF por medio del $\$ 38$ del Fondo de Previsión de la República Federal y de los Estados (FPRFE). La pensión de supervivencia para los trabajadores casados del servicio público en el marco del seguro complementario del FPRFE debe ser también aplicada desde el 1 de enero de 2005 a las parejas inscritas. La normativa acerca de la pensión de supervivencia, que solo beneficiaba a trabajadores casados, transgredía la norma constitucional. A diferencia del seguro de pensión legal, no había en el marco del seguro complementario del FPRFE una pensión de supervivencia para las parejas inscritas.

La pensión de supervivencia del FPRFE es una prestación del plan de pensiones y pertenece, por lo tanto, al ámbito de las remuneraciones. Por ello, no se reconoció ninguna diferencia entre los trabajadores casados y aquellos que viven como una pareja inscrita.

Cuando las condiciones generales de los seguros transgreden - como en el caso de la normativa del FPRFE - el art. 3 inc. 1, LF, ello implica que se debe llenar el vacío legal. La transgresión del principio de igualdad no puede

de aprobación sería constitucional o no. El TC señaló que la ley no contenía ninguna norma que requiriese de aprobación, según el art. 84, inc. 1, LF. Especialmente indicó que el precepto legal del $\$ 1$ LPI determinaba solo los requisitos jurídicos-materiales para la constitución del vínculo (Wellenhofer-Klein, 2003: 15).

52 BVerfG, Beschluss v. 07-07-2009 -1 BvR 1164/07. 
ser subsanado solo con la no aplicación del $\$ 38$ del FPRFE porque, en ese caso, tampoco podría aplicarse para el régimen del matrimonio. Por ello, la solución que se estableció fue que la disposición $\$ 38$ del FPRFE relativa a la pensión de supervivnecia para los cónyuges con aplicación desde el 1 de enero de 2005 también fuese aplicada para las parejas inscritas.

\section{LA SENTENCIA DEL TRIBUNAL CONSTITUCIONAL DE 18 DE JULIO DE $2012^{53}$.}

El Tribunal de Finanzas eleva una consulta al TC para que determine si el $\$ 3$ Nr. 4 de la Ley de Impuesto Territorial de Adqusición de Terrenos $(\mathrm{GrEStG})^{54}$ en la versión publicada de 26 de febrero de 19971997 (BGBl I S. 418) atenta contra el art. 3, inc. 1, LF, ya que la adquisición de un inmueble por una persona que vive como pareja inscrita no se encuentra liberado de pagar impuestos cuando la adquisicion ha sido efectuada por su pareja a diferencia del caso de un matrimonio, si el cónyuge adquiere un inmueble de su consorte está exento del pago del impuesto.

El hecho concreto que motivó la decisión del TC se refiere a una pareja inscrita en 2002 que vivía en régimen de participación en los gananciales. En

53 BVerfG, Beschluss v. 18-07-2012-1 Bvf 16/11.

$54 \$ 3$ Allgemeine Ausnahmen von der Besteuerung Von der Besteuerung sind ausgenommen: „[... ] der Grundstückserwerb von Todes wegen und Grundstücksschenkungen unter Lebenden im Sinne des Erbschaftsteuer- und Schenkungsteuergesetzes. Schenkungen unter einer Auflage unterliegen der Besteuerung jedoch hinsichtlich des Werts solcher Auflagen, die bei der Schenkungsteuer abziehbar sind; der Erwerb eines zum Nachlaß gehörigen Grundstücks durch Miterben zur Teilung des Nachlasses. Den Miterben steht der überlebende Ehegatte gleich, wenn er mit den Erben des verstorbenen Ehegatten gütergemeinschaftliches Vermögen zu teilen hat oder wenn ihm in Anrechnung auf eine Ausgleichsforderung am Zugewinn des verstorbenen Ehegatten ein zum Nachlaß gehöriges Grundstück übertragen wird. Den Miterben stehen außerdem ihre Ehegatten gleich; der Grundstückserwerb durch den Ehegatten des Veräußerers; (lo subrayado es mio) der Grundstückserwerb durch den früheren Ehegatten des Veräußerers im Rahmen der Vermögensauseinandersetzung nach der Scheidung; der Erwerb eines Grundstücks durch Personen, die mit dem Veräußerer in gerader Linie verwandt sind. Den Abkömmlingen stehen die Stiefkinder gleich. Den Verwandten in gerader Linie sowie den Stiefkindern stehen deren Ehegatten gleich; der Erwerb eines zum Gesamtgut gehörigen Grundstücks durch Teilnehmer an einer fortgesetzten Gütergemeinschaft zur Teilung des Gesamtguts. Den Teilnehmern an der fortgesetzten Gütergemeinschaft stehen ihre Ehegatten gleich“. 
2009 deciden separarse y liquidar el régimen de bienes, determinan el crédito de gananciales y cada uno adquiere del otro un inmueble con todas las cargas de este. El Tribunal de Finanzas le cobra a una persona por concepto de impuesto territoriales la suma correspondiente a $1811 €$ y, a la otra, la cantidad de $2699 €$ en consideración del valor de los inmuebles.

El problema fundamental radica en la diferencia de trato entre las parejas inscritas y las parejas matrimoniales, cuya justificación no es posible fundar en la especial protección constitucional del matrimonio. Asimismo, desde 2010 la discriminación relativa a las parejas inscritas no es factible, ya que la ley respectiva fue modificada.

Por lo tanto, el TC determinó la transgresión al principio de igualdad y ordenó al Ejecutivo adaptar la norma para los casos acaecidos con antelación al año 2011.

\section{LA SENTENCIA DEL TRIBUNAL CONSTITUCIONAL DE 7 DE MAYO DE $2013^{55}$}

En este caso, se determinó que los $₫ 26$ y $\$ 26$ b de la Ley de Impuestos a la Renta (LIR) en la versión publicada de 16 de abril de $1997^{56}$ y el $\$ 32 a$, inc. 5, LIR, en la versión relativa a la Ley de la Ley de Reducción de la Tasa de Impuestos y la Reforma de los Impuestos Empresariales (Steuersenkungsgesetz-StSenkG) de 23 de octubre de $2000^{57}$, como también la version posterior de $\$ \$ 26,26 b, \$ 32$ a, inc. 5 , LIR, eran tras la entrada en vigor de la LPI incompatibles con el art. 3, inc. 1, LF, puesto que, las parejas inscritas no podían hacer uso del procedimiento de partición de la renta, algo que sí era posible para las parejas casadas. También se estimó en consideración al art. 6, inc. $1, \mathrm{LF}$ que protege en especial al mantrimonio no justifica un tratamiento diferenciado en esta materia a las parejas inscritas. La especial consideración constitucional al matrimonio y a la familia garantiza no solo los cónyuges, sino a toda clase de familia la protección estatal.

\section{CONCLUSIONES}

En general, en cuanto al significado del principio de igualdad en el derecho tributario, se habla de justicia de los impuestos (Steuergerechtigkeit) ${ }^{58}$, lo

\footnotetext{
2 BvR 909/06; 2 BvR 1981/06; 2 BvR 288/07

Bundesgesetzblatt I, p. 821.

Bundesgesetzblatt I, p. 1433.

Stern et al. (2011: 1572).
} 
que se traduce, por ejemplo, en la orientación que debe dar la capacidad económica para efectos de los impuestos a la renta.

La doctrina alemana acepta parcialmente que al legislador se le reconoce una gran libertad de acción en cuanto a los impuestos, sobre todo en relación con la fijación de las tasas ${ }^{59}$. El TC, en su argumentación, reconoce la señalada libertad del legislador, sin embargo, establece sus límites, entre ellos, el Gebot de Ausrichtung des Steuerlast am Prinzip der finanziellen Leistungsfähigkeit y el Gebot de Folgerichtigkeit.

La Sentencia de 21 de julio de 2010 es continuadora de la línea jurisprudencial del TC relativa a la ausencia de argumentos jurídicos-materiales que permitan fundar la discriminación de las parejas inscritas en base al matrimonio. Wellenhofer-Klein, ya en el 2003, hacía presente la inconstitucionalidad de las normas de la LIHD, en razón de la evidente transgresión al art. 3, inc. 1, LF ${ }^{60}$.

El TC ha reconocido, sin embargo, la constitucionalidad del trato desigual entre matrimonios y uniones de hecho ${ }^{61}$, ya que, la situación en dichos casos es distinta, puesto que, en el matrimonio existe un institución de carácter formal, ya se indicaba al revisar los principios estructurales del matrimonio, entre ellos, se decía, el matrimonio civil con formalidades. En cuanto a las uniones de hecho, no existen dichas formalidades. Ahora bien, la diferenciación en materia de los tributos en razón de la herencia entre matrimonios y parejas inscritas no tiene ninguna justificación debido al reconocimiento jurídico de ambas instituciones y, por ello, tampoco los requerimientos formales para que ambas instituciones nazcan a la vida jurídica.

Tras la sentencia que impelía al legislador a modificar las normas tributarias relativas a la LIHD, el poder legislativo modificó las disposiciones legales. Aunque se debe indicar al respecto que existía ya con antelación un proyecto de ley del Gobierno alemán que igualaba la posición jurídica de las parejas inscritas a los cónyuges a partir de $2011^{62}$. Por lo tanto, a partir del 14

59 "[A] uch wird dem Gesetzgeber weitgehende Gestaltungsfreiheit bzw. ein weitreichender Entscheidungsspielraum insbesondere bei der Erschließung von Steuerquellen bzw. für Auswahl des Steuergegenstandes und Bestimmung des Steuersatzes eingeräumt. Dieses wenig konsistente Bild wird in der Rechtsprechung um Forderungen nach Systemgerechtigkeit bzw. der damit verwandten, häufig ausdrücklich auch auf die Umsetzung durch Verwaltung und Rechtsprechung erstreckten Folgerichtigkeit ergänzt« (Stern et al., 2011: 1574).

60 Wellenhofer-Klein (2003:186).

61 BVerfG NJW 1990,1593.

62 BVerfG, 1 BvR 611/07 vom 21-07-2010, inc. 1.122. Disponible en: http://www. bverfg.de/entscheidungen/rs20100721_1bvr061107.html. 
de diciembre de 2010, se estableció la total igualdad de parejas inscritas y cónyuges en relación con la $\mathrm{LIHD}^{63}$.

La sentencia establece una clara igualación tributaria entre matrimonio y parejas inscritas respecto a los impuestos, a la herencia y las donaciones. Con ello, sin duda, el derecho alemán está dando pasos afianzados para una total igualación de derechos entre los dos institutos jurídicos. Aunque para algunos autores, como Beck, la plena igualdad entre matrimonios y parejas inscritas aún no se ha logrado, el autor reconoce que se ha ido progresando ${ }^{64}$.

En síntesis, se puede observar la tendencia en el derecho alemán de aceptar la equiparación jurídica de la institución de las parejas inscritas al matrimonio, en el sentido de no permitir que, en razón de matrimonio, se discrimine a otra comunidad de vida reconocida por el ordenamiento jurídico alemán, esto es, a las parejas inscritas. A su vez, en razón de las disposiciones legales de otras ramas distintas al derecho civil, como lo son, el derecho de seguridad social y el derecho tributario, se amplía la aplicación de estas a materias que, tradicionalmente, solo han sido aplicables al matrimonio y no a otras comunidades de vida.

\section{Agradecimiento}

La autora agradece los comentarios y las críticas de los profesores Eduardo Aldunate, Rodrigo Barcia y Patricio Masbernat, como, asimismo, la ayuda de Jochen Taupitz respecto a la búsqueda bibliográfica.

\section{Bibliografía}

Badura, P. (2001). Ehe und Familie unter dem besonderen Schutze der staaatlichen Ordnung (art. 6, Abs. 1 GG). En Stiftung Gesellschaftsrecht für Rechtspolitik Trier (ed.). Bitburger Gespräche Jahrbuch (pp. 87-97). Trier: Universität Trier.

63 «Erbschaftsteuer bei eingetragenen Lebenspartnerschaften Die größten Steuervorteile des Jahresteuergesetzes erhalten eingetragene Lebenspartnerschaften.

Mit dem Jahressteuergesetz 2010 ist nun eine vollständige Gleichstellung von Lebenspartnern und Ehegatten im Erbschaftsteuer- und Schenkungsteuerrecht also auch in den Steuersätzen - vollzogen worden. Damit werden Lebenspartner im Erbschaft- und Schenkungsteuergesetz steuerlich den Ehegatten gleichgestellt. Die neue Regelung im Erbschaftsteuerrecht gilt für alle Erwerbe, also für Erbschaften und für Schenkungen ab Veröffentlichung des Jahressteuergesetzes 2010, d.h. ab dem 14.12.2010 und nicht erst ab dem 1. Januar 2011. Auch bei der Grunderwerbsteuer sind eingetragene Lebenspartner den Ehegatten nun gleichgestellt». Disponible en: http://www.finanztip.de/recht/steuerrecht/erbschaftssteuerreform.htm.

Beck (2010: 12-14). 
Barcia, R. y Riveros, C. (2011). El carácter extrapatrimonial de la compensación económica. Revista Chilena de Derecho, 38, 249-278.

Beck, M. (2010). Wider die Diskriminierung. BVerfG stärkt homosexuelle Lebenspartnerschaften. NJW Aktuell, 36, 12-14.

Bosch, F. (1954). Zur Neuordung des ehelichen Güterrechts. FamRZ, 6, 149-156.

Di Fabio, U. (2003). Der Schutz von Ehe und Familie: Verfassungsentscheidung für die vitale Gesellschaft. NJW, 14, 993.

Frank, R. (2003). Erbrecht. München: C. H. Beck.

Gernhuber, J. (1981). Ehe und Familie als Begriff des Recht. FamRZ, 8, $72-727$.

Grziwotz, H. (2010). Art. 3 I GG: Ungleichbehandlung von Ehe und Lebenspartnerschaft im Erbschaft und Schenkungsteuerrecht. FamRZ, 18, 1532-1534.

Kessal-Wulf, S. et al. (1999). Münchener Kommentar zum Bürgerliches Gesetzbuch. Tomo 9 Erbrecht (\$\$ 1922-2385 BGB). München: C. H. Beck.

Kingreen, T. (1997). Das Grundrecht von Ehe und Familie. Jura, 8, 401-406.

Larenz, K. y Wolf, M. (2004). Allgemeiner Teil des Bürgerliches Rechts. München: C. H. Beck.

Lecheler, H. (1979) Der Schutz der Familie. FamRZ, 1, 1 y ss.

Messner, M. (2010). Lebenspartnerschaft. Steuerliche Konsequenzen des BVerfG-Beschlusses vom 21-07-2010, DStR, 37, 1875 -1879.

Muscheler, K. (2010). Die Reform des Lebenspartnerschaftsrechts, FPR, 5, 227-236.

Ott, S. (1998). Die Begriffe Ehe und Familie in art. 6 I GG. NJW, 3, 117-119.

Rauscher, T. (2001). Familienrecht. Heidelberg: C. F. Müller.

Riveros, C. y López, Y. (2008). El divorcio en el derecho de familia chileno, alemán y costarricense. Revista del Poder Judicial de Costa Rica, 89, 85-127.

Romswinkel, M. (2011). Das Bundesverfassungsgericht zu Lebenspartnerschaften im Erbschaftsteuerrecht. Gedanken eines Steurerberaters. ZTEu, 277-279.

Schlüter, W. (2006). Familienrecht. Heidelberg: C.F. Müller.

Schneider, H. (2010). Die Besteuerung eingetragener Lebenspartnerschaften. StC, 10, 277-279.

Schwab, D. (1976). Zur Geschichte des verfassungsrechtlichen Schutzes von Ehe und Familie. FS Bosch, 893-908.

Schwab, D. (2009). Familienrecht. Heidelberg: C. F. Müller.

Schwab, D. et al. (2000) Münchener Kommentar zum Bürgerliches Gesetzbuch. Band 7 Familienrecht I (\$\$ 1297-1588), München: C. H. Beck.

Strohal, F. (2010). Steuerrechtliche Gleichbehandlung eingetragener Lebenspartner und Ehegatten? FamFR, 481-483.

Steiner, U. (2005). Zum Ehebild in der jüngeren Rechtsprechung des Bundesverfassungsgerichts. S. Hofer et al. (eds.). Perspektiven des Familienrechts, Festschrift für Dieter Schwab zum 70. Geburtstag (pp. 433-442). Bielefeld: Gieseking.

Stern, K. Sachs, M. y Dietlein, J. (2011). Das Staatsrecht der Bundesrepublick Deutschland, Band IV/2. Die Einzelnen Grundrechten. München: C. H. Beck.

Von Münch, I., Kunig, P. y Waltjen-Coester, D. (2000). Grundgesetz-Kommentar, Band 1, 5. München: C. H. Beck.

Waltjen-Coester, D. (2008). Art. 6 GG und der Schutz der Ehe. Jura, 2, 108-111. 